\title{
Relationship of the Presence of Lingual Concavity and Mandibular Canal Location:
}

\section{A Retrospective Two-Center Study*}

Lingual Konkavite Varliği ve Mandibular Kanal Lokasyonu ilişkisi: İki Merkezli Retrospektif Çalışma

\author{
Nazan Kocak Topbasi, Mehmet Ozgur Ozemreii, Canan Uzuniii, Büyük Kaan Orhaniv, Ayse Gulsahiv, Paul
} van der Stelt" , Oya Seker" ${ }^{\mathrm{vII}}$, Kıvanc Kamburoglu vi"I

\begin{abstract}
'Asst.Prof.Dr., Mersin University, Faculty of Dentistry, Department of Dentomaxillofacial Radiology, https://orcid.org/0000-0002-3717-2098
iAsst.Prof.Dr., Mersin University, Faculty of Dentistry, Department of Dentomaxillofacial Radiology, https://orcid.org/0000-0001-5863-6990 iii'Asst.Prof.Dr., Health Science University, Faculty of Dentistry, Department of Dentomaxillofacial Radiology, https://orcid.org/0000-0001-8940-5191 ivAssoc.Prof.Dr., Baskent University, Faculty of Dentistry, Department of Dentomaxillofacial Radiology, https://orcid.org/0000-0003-1686-4746 vProf.Dr., Baskent University, Faculty of Dentistry, Department of Dentomaxillofacial Radiology, https://orcid.org/0000-0003-1990-1637

v'Prof.Dr., Academic Centre for Dentistry in Amsterdam, Department of Dentomaxillofacial Radiology, https://orcid.org/0000-0002-2501-2484 v"Asst.Prof.Dr., Hatay Mustafa Kemal University, Faculty of Dentistry, Department of Restorative Dentistry, https://orcid.org/0000-0001-9621-1811

vi'Prof.Dr., Ankara University, Faculty of Dentistry, Department of Dentomaxillofacial Radiology, https://orcid.org/0000-0002-4134-5756
\end{abstract}

\section{ABSTRACT}

Aim: To evaluate the possible relationship between the position of the mandibular canal (MC) on digital panoramic images (PI) and the presence of a lingual concavity (LC) on Cone-Beam Computed Tomography (CBCT) scans in two different populations.

Materials and methods: In this retrospective study, the digital archives of a private imaging center in Turkey and at The Academic Center for Dentistry Amsterdam (ACTA) in Netherlands patients who had both panoramic and CBCT images, taken between January 2016 and June 2016 due to various indications. A total of 248 patients were assessed. MC position was defined on digital panoramic radiographs; the presence of LC was assessed on CBCT images. In all statistical methods, $p$ value $<0.05$ was considered statistically significant. The Mc Nemar test and the receiver operating characteristics (ROC) curve analysis (AZ), were performed for data analysis.

Results: Considering all patients, the presence of LC was $28 \%$ and $31 \%$ for the left and right premolar regions and $75 \%$ and $77 \%$ for the left and right molar regions, respectively. There was no significant difference between right and left sides and between the Turkish and Dutch populations with respect to the presence of $\mathrm{LC}$. Considering all patients, the presence of a LC was higher in the molar region than in the premolar region for both right and left sides with a statistical significance $(p<0.001)$.

Conclusions: The higher percentages of LC in the molar region in both populations suggests that a preoperative local CBCT assessment is justified specifically before implant placement in the mandibular molar region. The location of the MC on the PI was not a very strong indication of the presence of a LC.

Keywords: Anatomy, Cone beam computed tomography, Lingual concavity, Mandibular canal, Panoramic radiography

öz

Amaç: Dijital panoramik görüntülerde (PG) mandibular kanalın (MK) konumu ile Konik Işınlı Bilgisayarlı Tomografi (KIBT) taramalarında lingual konkavlığın (LK) varlığı arasındaki olası ilişkiyi iki farklı popülasyonda değerlendirmek.

Gereç ve yöntem: Bu retrospektif çalışmada, Türkiye'deki özel bir görüntüleme merkezi ve Hollanda'da Amsterdam Diş Hekimliği Akademik Merkezi'nde (ADAM) hem panoramik hem de KIBT görüntüleri olan hastaların Ocak 2016-Haziran 2016 tarihleri arasında çeşitli endikasyonlar nedeniyle çekilmiş dijital arşivleri incelenmiştir. Toplam 248 hasta değerlendirildi. MK pozisyonu, dijital panoramik radyograflarda tanımlandı. KIBT görüntülerinde LK varlığı değerlendirildi. Tüm istatistiksel yöntemlerde $p$ değeri $<0,05$ istatistiksel olarak anlamlı kabul edildi. Veri analizi için Mc Nemar testi ve alıcı işletim karekteristiği (ROC), eğri analizi (AZ) yapıldı.

Bulgular: Tüm hastalar dikkate alındığında sol ve sağ premolar bölgelerinde LK varlı̆ı sırasıyla $\% 28$ ve $\% 31$, sol ve sağ molar bölgelerinde sırasıyla \%75 ve \%77 idi. LK varlığı açııından sağ ve sol taraflar arasında ve Türk ve Hollanda popülasyonları arasında anlamlı bir fark yoktu. Tüm hastalar dikkate alındığında, molar bölgede hem sağ hem de sol taraf için premolar bölgeye göre LK varlı̆̆ı istatistiksel olarak anlamlı olarak daha yüksekti ( $p<0.001)$. Sonuçlar: Her iki popülasyonda molar bölgedeki daha yüksek LK yüzdeleri, mandibular molar bölgeye implant yerleştirmeden önce ameliyat öncesi bir lokal KIBT değerlendirmesinin özellikle doğrulandığını düşündürmektedir. MK'nın PG üzerindeki konumu, bir LK'nin varlığının çok güçlü bir göstergesi değildi.

Anahtar Kelimeler: Anatomi, Konik ışınlı bilgisayarlı tomografi, Lingual konkavite, Mandibular kanal, Panoramik radyografi

\footnotetext{
"Mersin Üniversitesi Tıp Fakültesi Lokman Hekim Tıp Tarihi ve Folklorik Tıp Dergisi, 2022; 12 (1): 170-178 DOI: 10.31020/mutftd.1022145

e-ISSN: 1309-8004, ISSN 1309-761X

Geliş Tarihi - Received: 11 November 2021; Kabul Tarihi - Accepted: 14 December 2021

iletişim - Correspondence Author: Nazan Koçak Topbaş <nazannkocak@gmail.com>

Ethical Approval: Başkent University Institutional Review Board (Date: 07/10/2015, number: 94603339-

604.01.02/6827)
} 


\section{Introduction}

Dental implant operations play an important role in the treatment of partially or completely edentulous jaws in routine dental practice. ${ }^{1-4}$ The realization of a successful operation is possible with a detailed analysis of the anatomical structures and their neighborhood. ${ }^{1,3,5}$ Complications such as mandibular canal (MC) or lingual plate perforation may develop in the posterior and anterior regions of the mandible. ${ }^{1}$ Paraesthesia in the jaw, anesthesia, loss of vitality in the teeth, inflammation, infection and ultimately implant loss may occur. ${ }^{1-4}$

In the posterior mandible, the lingual concavity (LC) below the mylohyoid ridge and the MC show variations that have the potential to restrict implant placement. ${ }^{6}$ Previous studies showed that the LC in the molar region has an incidence of $66-68 \%{ }^{1,2}$ Therefore, placing the implant in the correct position is of paramount importance in order to avoid lingual plate perforation and assure long term implant stability. ${ }^{2,4,5}$

The alveolar ridge morphology can be assessed by palpation, implantology caliper and model analysis. However, as these methods prolong the duration of the surgery, the comfort of both the patient and the clinician decreases and thus various limitations and disadvantages occur in the success of the process. Another method to examine bone morphology is the radiographic assessment of the implant site. ${ }^{2}$

Radiographic examinations are used for preoperative dental implant site assessment. ${ }^{6,7}$ Although conventional two-dimensional radiographs are inexpensive and easily accessible, they have several limitations such as magnification, distortion and superimposition of adjacent anatomical structures. In addition, it is impossible to assess the bucco-lingual dimensions when using 2-dimensional images. ${ }^{4,5,7}$

Cone Beam Computed Tomography (CBCT) is an innovative and relatively recent technique providing highly accurate 3D measurements through multi-planar (axial, sagittal, coronal, and cross-sectional) reconstructions. ${ }^{8-10}$ The American Academy of Oral and Maxillofacial Radiology (AAOMR) recommends the use of cross-sectional imaging for the evaluation of potential implant sites. ${ }^{6}$ The European Guidelines for $C B C T$ suggest to use $C B C T$ imaging when conventional $2 D$ radiographs do not provide enough information or when the dose of $C B C T$ is less than that of a set of $2 \mathrm{D}$ radiographs. ${ }^{11}$ Although, $\mathrm{CBCT}$ images provide three dimensional and accurate information regarding mandibular morphology, it should not be routinely used due to the higher radiation dose and cost when compared to conventional radiographs., ${ }^{7,10}$

Today, although CBCT is recommended before implant operations, implant plannings are performed on PIs for reasons such as $\mathrm{CBCT}$ is not available in all centers. The primary aim of this study was to investigate the possibility of detecting the presence of $\mathrm{LC}$, which may result in implant operation complications, by examining the course of MC on PIs. When the LC is relatively deep, lingual cortical perforation has the potential to occur during implant placement and its presence imposes anatomical limitations on the site. ${ }^{2}$ There are numerous studies which aim at the assessment of the anatomic variations of the mandible. $1,2,4,5,12,13$

Health and disease are social and cultural as well as biological phenomena. This socio-cultural phenomenon gives rise to a sociological perspective and examines cause-effect relationships in this field. Social environment, human characteristics are different factors that make up the distribution of diseases. These phenomena can vary from society to society, and they may also show differences within the same society. ${ }^{14}$ The varying risk factors ( $M C$ and $L C$ ) of different societies constitute the parameters of our study. Epidemiology is another subject that the sociology of health is related to. ${ }^{14}$ In our study, it is stated that the presence of lingual concavity can lead to various complications. Our study has been a valuable sociological and epidemiological study evaluating the presence and absence of LC under the topics of health and disease.

Therfore, it should also be taken into account that there may be racial differences in the depth of concavity. However, as far as we know, there has been no study comparing the Turkish population with a different race 
(Dutch population) on lingual concavity. With this study, it was secondarily aimed to evaluate the presence of $L C$ and $M C$ relationship between two sociologically different ethnic groups and to prevent complications that may occur during implant operations. A recent study concluded that there was a relationship between the presence of $\mathrm{LC}$ and the inferior location of the $\mathrm{MC}$ in edentulous patients. ${ }^{1}$ Based on this finding, the main aim of the present retrospective study was to evaluate the possible relationship between the position of the MC on digital PIs and the presence of a LC on CBCT scans in two different populations.

\section{Materials and Methods}

This study was approved by Başkent University Institutional Review Board (Decision date: 07/10/2015, decision number: 94603339-604.01.02/6827, project no: D-KA15/18) and the protocol of the study was conducted following the principles of the Declaration of Helsinki. The PI and CBCT images of the patients taken between January 2016 and June 2016 due to various indications were retrospectively collected from the digital archives of a private imaging center in Ankara (Turkey) and the archives of the Academic Center for Dentistry Amsterdam (ACTA) University (Amsterdam, Netherlands). Patients who had both panoramic and $\mathrm{CBCT}$ images which displayed the whole mandible were selected. Both dentulous and edentulous area were included the study. Informed consent form was signed by all participants included in the study.

\section{Inclusion and exclusion criteria}

In the study, 280 patients who had both panoramic and CBCT images were included. X-ray shooting indications have been determined for various dental situations such as the presence of jaw pathology, orthodontic problems and implant planning in the acquisition of panoramic and CBCT images. Thirty-two patients who had images with artifacts or pathology (cysts, tumors etc.) extending into the region of the mental foramen and severe periodontal problems such as horizontal and vertical bone resorption were excluded from the study. In addition, images with not clear superior border of the MC were also excluded from the study. Consequently, a total of 248 patients, 148 Turkish patients from Ankara and 100 Dutch patients from Amsterdam were included in the present study. Age and gender of the patients were also recorded.

Two observers (senior research assistants at the dentomaxillofacial radiology department with two and four years of experience) examined the CBCT and PIs of both patient groups under the supervision of a dentomaxillofacial radiologist with 11 years of experience.

\section{Panoramic measurements}

The digital PIs were taken with a Proline XC (Planmeca, Helsinki, Finland) in Ankara and an Orthopantomograph OP 100 D, Orthopantomograph OP 300 (both Instrumentarium Imaging, Tuusula, Finland) and Proline XC (Planmeca, Helsinki, Finland) at The Academic Centre for Dentistry in Amsterdam (ACTA).

All PIs were recorded as digital files in JPEG format with a resolution of $300 \mathrm{dpi}$ and were examined in a computer-aided drawing program (ImageJ, National Institutes of Health, Bethesda, MD). Before the measurements, the calibration was performed with the straight line selection tool to select a line that corresponds to a known distance. Viewing was conducted in a dimmly light room. In order to standardize brightness and contrast, it was decided not to make improvements when viewing images. Another possible confounding factor was the computer monitor's brightness and contrast setting. Therefore, the brightness and contrast setting were set to the maximum setting in each evaluation.

The measurements were performed on both first premolar and second molar regions. The distal side of the mental foramen on PIs considered as the first premolar region. The second molar region was considered as 
$18 \mathrm{~mm}$ posterior from the first premolar region in the edentulous patient. In order to define the position of the $M C$ in the digital PIs, the distance between the superior border of the $M C$ and the alveolar crest was measured as well as the total vertical dimension of the mandible (Figure 1). If the proportion of the distance from the $M C$ to the superior border of the alveolar crest was equal to or more than $60 \%$, the $M C$ was considered as located deeply, if it was less than $60 \%$, the MC was considered as located superficial. ${ }^{1}$

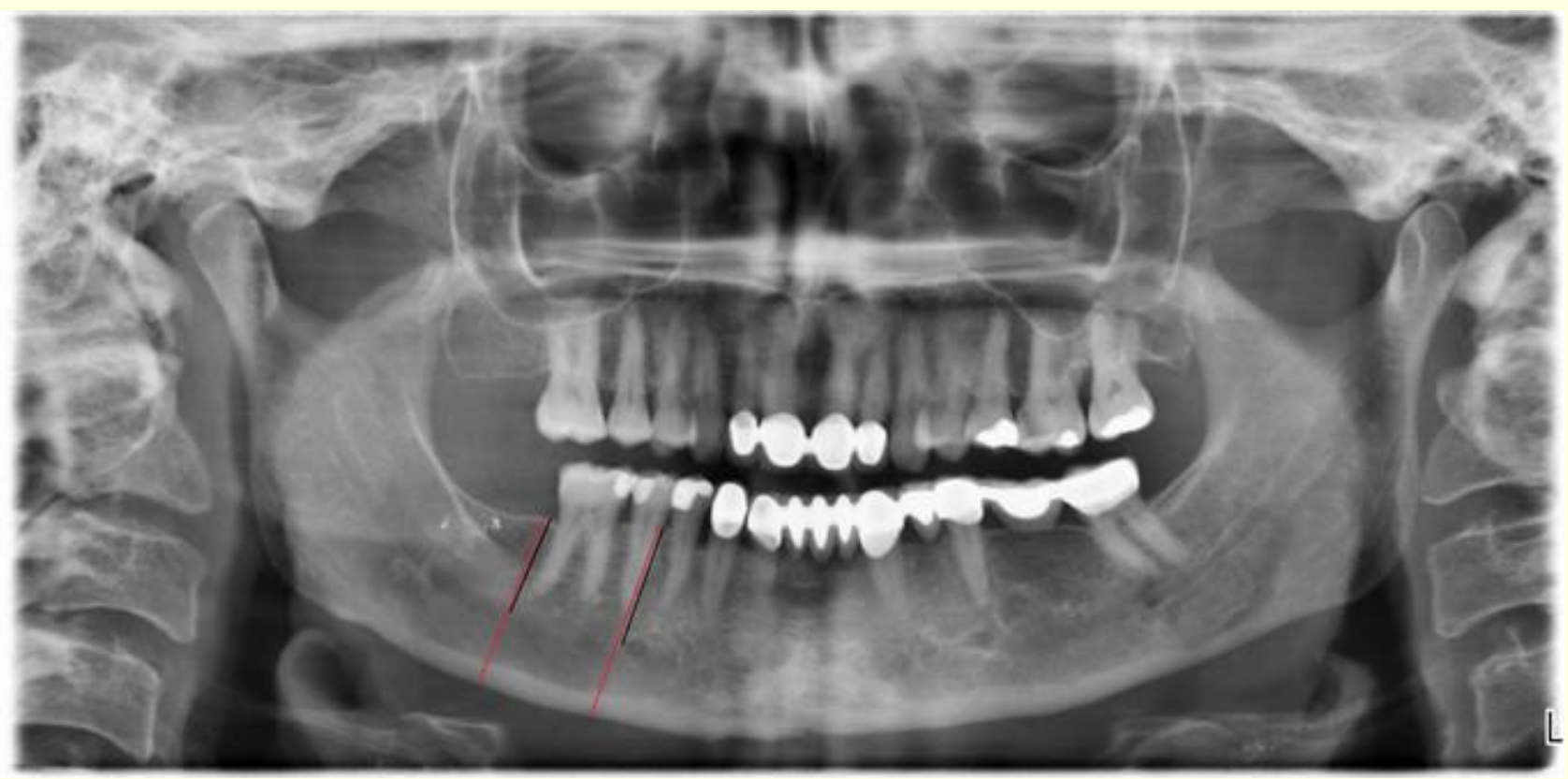

Figure 1. Panoramic images showing the measurements made on premolar and molar regions for the right side

\section{CBCT measurements}

CBCT images were obtained by an ILUMA (OrthoCAT ${ }^{\text {TM }}$, IMTEC Imaging IMTEC Plaza 2401, North Commerce Ardmore, Oklahoma, USA) in Ankara and a 3D Accuitomo 170 (J Morita Mfg. Corp., Kyoto, Japan) and NewTom 5G (QR s.r.l., Verona, Italy) at Amsterdam. The images were analyzed using the proprietary software of each machine. While the CBCT images were assessed, the vertical orientation was aligned with the patient's sagittal plane, and the horizontal line (Frankfort plane) parallel to the floor. Cross-sectional images with $1 \mathrm{~mm}$ slice thickness and $1 \mathrm{~mm}$ slice interval were created. The LC was assessed in two different mandibular regions. The section on which the mental foramen could clearly be observed was considered as the first premolar region. The second molar region was considered as the region, $18 \mathrm{~mm}$ posterior to the first premolar region. On the mandibular lingual region, a tangent line was drawn from the top of alveolar crest to the inferior border of the mandible on cross-sectional images. If the lingual mandibular bone reached straight down without curvature in the vertical direction, it was accepted as LC was absent. The presence (Figure 2) or absence (Figure 3) of a LC was evaluated in these two regions. 


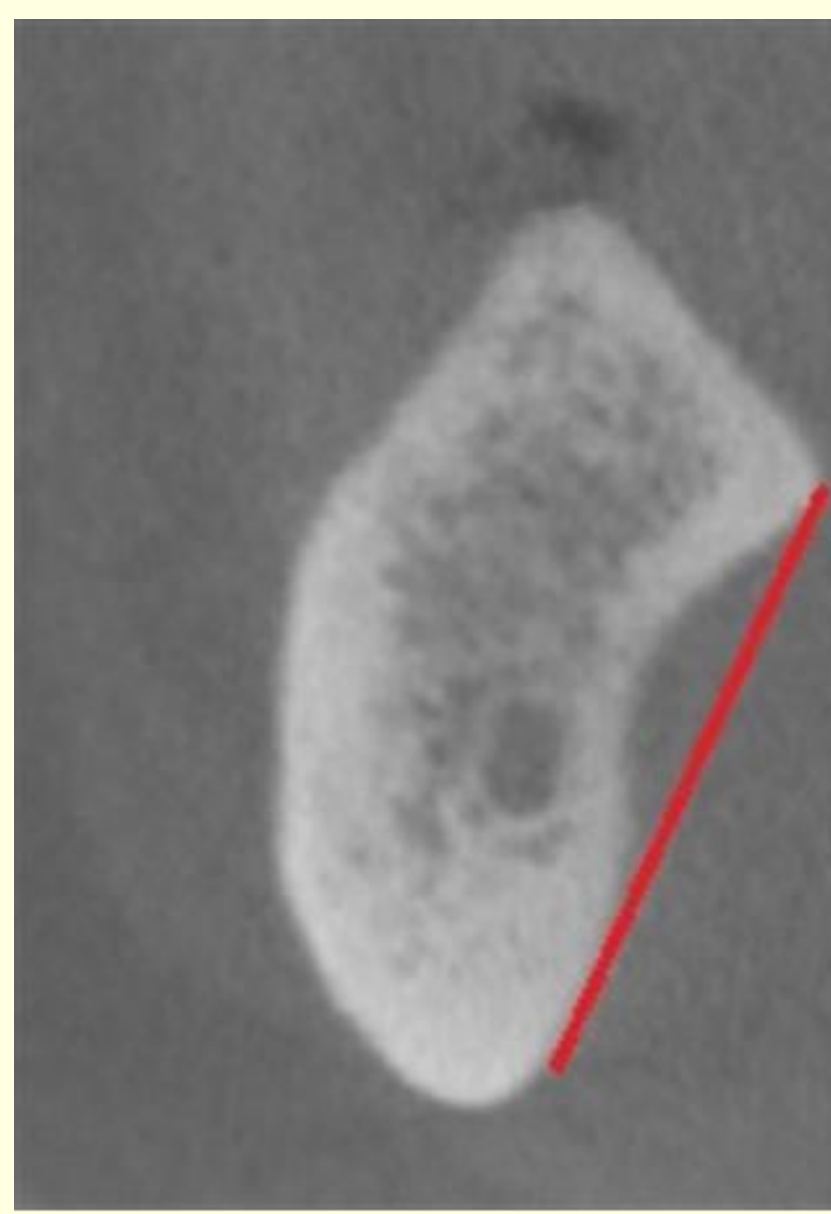

Figure 2. Presence of lingual concavity as shown in a crosssectional CBCT image

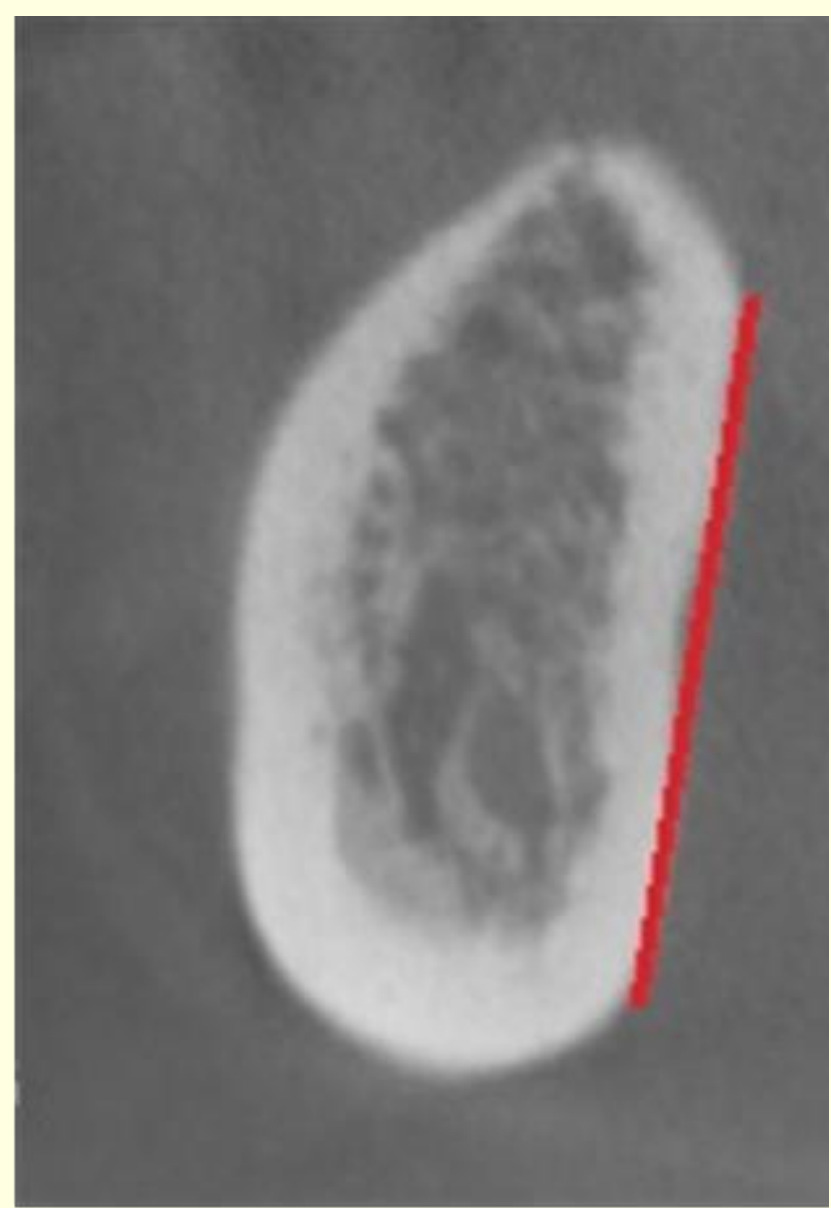

Figure 3. Cross-sectional image, showing the absence of a lingual concavity

\section{Reliability}

One observer served as the main observer and intra-observer reliability was calculated for the main observer. The images of 30 Turkish patients were randomly selected from the sample and assessed twice with a two weeks' intervals by the main observer in order to quantify intra-observer agreement. The other observer evaluated the same 30 images to assess the inter-observer reliability. Intra-and inter-observer agreement was assessed by kappa ( $\mathrm{k}$ ) statistics for CBCT (because of the categorical variable) and by intraclass correlation coefficient (ICC) for panoramic measurements (because of the continuous variable). $\mathrm{k}$ values for the $\mathrm{CBCT}$ observations were interpreted according to the following criteria: $<0.40$ : poor agreement; 0.40 0.75: fair to good agreement; $>0.75$ excellent agreement. ${ }^{15} \mathrm{ICC}$ values for the panoramic observations were interpreted according to the following criteria: $<0.40$ : poor agreement; $0.50-<0.75$ : moderate agreement; $0.75-<0.90$ good agreement; $0.90-1.00$ excellent agreement. ${ }^{16}$

\section{Statistical Analysis}

Statistical analysis was performed using SPSS for Windows (SPSS 20.0, Chicago, IL, USA). In all statistical methods, $p$ value $<0.05$ was considered statistically significant. The Mc Nemar test was performed to determine whether the percentage of the presence of LC differed between the left and right sides and the premolar and molar regions.

The receiver operating characteristics $(R O C)$ curve analysis $\left(A_{z}\right)$ was used to clarify whether patients with LC could be identified accurately using the inferior location of the MC. The cut-off threshold was shifted systematically over the measurement range and observed pairs of sensitivity and ( 1 - specificity) were 
established for each different operating point. Based on these observed pairs, the ROC curve was obtained and the area under the ROC curve (AUC) was calculated. Thus, an $A_{z}$ value of 1 corresponds to a perfect discrimination, whereas a value of 0.5 corresponds to just chance without discrimination ability. Therefore, $A_{z}$ values were compared using $z$ tests against $A_{z}=0.5$

\section{Results}

The intra-observer agreement was good for panoramic (ICC $\geq 0.86)$ and excellent for CBCT $(\kappa \geq 0.81)$. Inter-

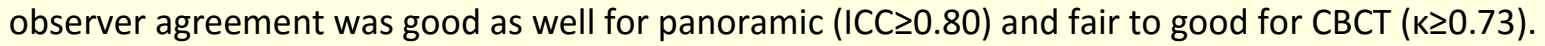

A total of 248 subjects were assessed. Distribution of patients according to age, gender and dental status is presented in Table 1. The presence of LC was not associated with gender, age groups or dental status $(p>0.05)$.

Table 1. Age and sex of the study population

\begin{tabular}{llll}
\hline & Turkey & Netherlands & Total \\
\hline $\begin{array}{l}\text { Mean age } \mathbf{S D} \\
\text { Sex } \mathbf{n}(\%)\end{array}$ & $50.5 \pm 16.3$ & $46.4 \pm 14.5$ & $56.5 \pm 17.1$ \\
Female & & & \\
Male & $81(55 \%)$ & $63(63 \%)$ & $144(58 \%)$ \\
Dental status & $67(45 \%)$ & $37(37 \%)$ & $104(42 \%)$ \\
Dentate & & & \\
Edentulous & $142(96 \%)$ & $61(61 \%)$ & $203(82 \%)$ \\
\hline
\end{tabular}

SD: Standart Deviation

The presence of $\mathrm{LC}$ according to the anatomical region in the two population groups is presented in Table $\mathbf{2}$. There was no significant difference between right and left sides $(p>0.05)$ and between the Turkish and Dutch populations ( $p>0.05$ ) with respect to the presence of LC. Considering all patients, the presence of a LC was higher in the molar region than in the premolar region for both right and left sides with a statistical significance $(p<0.05)$. Similar results were found when the presence of $L C$ was evaluated separately for the two different populations $(p<0.05)$.

Table 2. Percentages of lingual concavity according to region and studied population.

\begin{tabular}{|c|c|c|c|c|c|c|c|c|c|}
\hline & \multicolumn{2}{|c|}{ Turkey (n:148) } & \multirow[b]{2}{*}{$\mathbf{P}^{*}$} & \multicolumn{2}{|c|}{ Netherlands ( $\mathrm{n}: 100)$} & \multicolumn{4}{|c|}{ Total $(n: 248)$} \\
\hline & Right & Left & & Right & Left & $\mathbf{P}^{*}$ & Right & Left & $\mathbf{P}^{*}$ \\
\hline \multicolumn{10}{|l|}{ Premolar } \\
\hline Presence & $40(27 \%)$ & $41(28 \%)$ & & $36(36 \%)$ & $29(29 \%)$ & & $76(31 \%)$ & $70(28 \%)$ & \\
\hline Absence & $108(73 \%)$ & $107(72 \%)$ & 1.00 & $64(64 \%)$ & $71(71 \%)$ & 0.167 & $172(69 \%)$ & $178(72 \%)$ & 0.451 \\
\hline \multicolumn{10}{|l|}{ Molar } \\
\hline Presence & $108(78 \%)$ & $113(76 \%)$ & & $75(75 \%)$ & $73(73 \%)$ & & 190(77\%) & 186 (75\%) & \\
\hline Absence & $33(22 \%)$ & $35(24 \%)$ & 0.856 & $25(25 \%)$ & $27(27 \%)$ & 0.832 & $58(23 \%)$ & $62(25 \%)$ & 0.678 \\
\hline $\mathrm{P}^{* *}$ & 0.000 & 0.000 & & 0.000 & 0.000 & & 0.000 & 0.000 & \\
\hline
\end{tabular}

$\mathrm{P*}$ comparison of right and left sides with Mc-Nemar test, $\mathrm{P}^{* *}$ comparison of premolar and molar regions with Mc-Nemar test

The relationship between the presence of a $L C$ and the inferior location of the $M C$ is shown in Table 3. A high $A_{z}$ value means that the location of the $M C$ can be used as an indicator of the presence of a $L C$ and a lower $A_{z}$ means that the location of the $M C$ is not a reliable indicator. The $A_{z}$ values in the right premolar and molar regions were not very high, although they were statistically significant for the two comparisons $(p<0.05)$. There was no significant difference in the left premolar and molar regions for both populations, $(p>0.05)$. These results seem to suggest that the inferior location of the MC can be used for the detection of LC on the right side. On the left side, however, the outcome was not statistically significant. Therefore, this result does not have a clinical relevance. Similar results were also found when the two different populations were evaluated separately (Table 3). 
Table 3. Area Under the Curve (AUC) value, their Standard Error (SE), 95\% Confidence Interval (CI) and significance levels (p) or the relationship between the presence of lingual concavity and the inferior location of the MC.

\begin{tabular}{|c|c|c|c|c|c|c|}
\hline & \multicolumn{2}{|c|}{ Turkey } & \multicolumn{2}{|c|}{ Netherland } & \multicolumn{2}{|c|}{ Total } \\
\hline & Right & Left & Right & Left & Right & Left \\
\hline \multicolumn{7}{|l|}{ Premolar } \\
\hline$A \cup C$ (SE) & $0.607(0.051)$ & $0.551(0.052)$ & $0.639(0.056)$ & $0.547(0.064)$ & $0.591(0.039)$ & $0.537(0.041)$ \\
\hline$\% 95 \mathrm{Cl}$ & $(0.506-0.708)$ & $(0.450-0.652)$ & $(0.529-0.749)$ & $(0.422-0.672)$ & $(0.515-0.677)$ & $(0.457-0.617)$ \\
\hline $\mathrm{p}^{*}$ & 0.046 & 0.338 & 0.021 & 0.459 & 0.022 & 0.366 \\
\hline \multicolumn{7}{|l|}{ Molar } \\
\hline AUC (SE) & $0.587(0.057)$ & $0.519(0.053)$ & $0.646(0.073)$ & $0.609(0.067)$ & $0.597(0.046)$ & $0.557(0.042)$ \\
\hline$\% 95 \mathrm{Cl}$ & $(0.475-0.699)$ & (0.414-0.623) & $(0.503-0.788)$ & $(0.478-0.741)$ & $(0.508-0.687)$ & $(0.474-0.640)$ \\
\hline$P^{*}$ & 0.128 & 0.740 & 0.030 & 0.095 & 0.025 & 0.179 \\
\hline
\end{tabular}

AUC: Area Under the Curve, SE: Standard Error, Cl: Confidence Interval, ${ }^{*}$ Comparison of Null hypothesis true area $(p):=0.5$

The first cut-off values were 0.60 for both premolar and molar regions and the $A_{z}$ values were not high. In order to obtain more accurate $A_{z}$ results, the cut-off value in the molar region was changed to 0.50 (Table 4). According to this cut-off value, the sensitivity values were $0.487-0.543$ for the premolar region and 0.780 0.789 for the molar region. The specificity values were 0.622 and 0.640 for left and right premolar regions and 0.323 and 0.397 for left and right molar region respectively.

Table 4 The sensitivity and specificity values for 0.60 and 0.50 cut-off values for premolar and molar regions.

\begin{tabular}{lccccc}
\hline & $\begin{array}{c}\text { Positive if greater } \\
\text { than or equal to }\end{array}$ & Youden's Index & Cut-off value & Sensitivity & Specificity \\
\hline Right Premolar & 0.587 & 0.195 & 0.60 & 0.487 & 0.622 \\
Right Molar & 0.478 & 0.223 & 0.50 & 0.789 & 0.397 \\
Left Premolar & 0.585 & 0.187 & 0.60 & 0.543 & 0.640 \\
Left Molar & 0.484 & 0.113 & 0.50 & 0.780 & 0.323 \\
\hline
\end{tabular}

\section{Discussion}

Clinicians must have accurate information regarding the bone anatomy and the osseous topography of the surgical site in order to optimize implant placement and in order to avoid surgical complications. ${ }^{17,18}$ Various authors have suggested that $\mathrm{CBCT}$ is an appropriate technique for the assessment of mandibular morphology, because of its submillimeter accuracy in three dimensions. ${ }^{2,4,12,19}$ Transverse CBCT images are useful in the assessment of the cross-sectional morphology of the posterior mandible and for the detection of $\mathrm{LC}^{2,16}$ When the $\mathrm{LC}$ is relatively deep, lingual cortical perforation has the potential to occur more readily during the implant placement. ${ }^{2,18}$

Studies revealed that a $L C$ is a common finding in the posterior mandible and were found in $66-68 \%$ of the cases in the molar region. ${ }^{1,2,4}$ However, Watanabe et al. reported presence of a LC in only $36-39 \%$ in the mandibular molar region. ${ }^{5}$ It is possible that the differences are based on the ethnic composition of the patient populations. While Watanabe et al. focused on a Japanese population, Chan et al. and our study included mixed populations. ${ }^{2,5}$ According to our results, the presence of a LC in the molar region was equal to or greater than $73 \%$ in samples from Turkey and the Netherlands, separately and in the total sample.

Another factor affecting the presence of LC is the dental status of the patients. It is well known that LC is more common in the edentulous mandible. ${ }^{1}$ In this study both dentulous and edentulous subjects were included, but no difference was observed according to dental status. Interestingly, LC was detected in 73\% to $77.7 \%$ in the mandibular molar region. Based on the results of our study, a significant number of examined subjects had a LC posing potential perforation risk.

To avoid perforation risk during implant placement, cross-sectional analysis of the region by CBCT may be recommended. Considering the radiation dose, costs and time, CBCT assessment of all implant sites is not justified. ${ }^{4}$ This study aimed to assess the possible relationship between the presence of LC and the inferior 
location of $\mathrm{MC}$ position, because this information can rather easily be extracted from a panoramic radiograph. Therefore, if a positive relationship is detected between these two parameters, patients with inferior location of $\mathrm{MC}$ on PIs may be referred for $\mathrm{CBCT}$ examination in order to avoid lingual plate perforation. Since sensitivity or specificity values were not higher than previous values determined by Nickenig et al. ${ }^{1}$ it was concluded that inferior location of the MC may not be a strong diagnostic criteria for the detection of LC.

In addition, to the best of our knowledge, no study evaluating lingual concavity with magnetic resonance imaging (MRI) and ultrasonography (USG) could be found in the literature, unlike our study. However, a few studies evaluating lingual concavity with CT have been found and they are not similar to the subject of our study. ${ }^{20,21}$

The presented study has limitations related to the retrospective design and limited sample size. Therefore, age, gender and radiographic information of the patients were only assessed in this study. However, the duration of being edentulous, chewing habits of the patients, complications during the extraction and patients' systemic conditions, all of these factors may affect the bone architecture and the position of the MC.

\section{Conclusion}

In conclusion, within the limits of this study the higher percentages of LC in the molar region in both populations suggests that, preoperative regional CBCT assessment should be performed specifically before implant placement in the mandibular molar region. The location of the $\mathrm{MC}$ on the PI was not a very strong indication of the presence of a concavity. This study also focused on the social and ethnic aspects of the sociology of health and medicine and revealed the cause-effect relationships. It has been also noted that useful findings can be obtained from this aspect in diagnosis and treatment planning.

\section{Acknowledgement}

The authors report no actual or potential conflicts of interest. This research supported by Baskent University Research Fund (Project No: D- KA15/18).

Ethical approval: Prior to the study, approval was obtained from the Baskent University Institution Review Board (Decision date: 07/10/2015, decision number: 94603339-604. 01.02/6827), and consent was obtained from all patients.

\section{Author contributions}

Nazan Koçak Topbaş: Conceptualization, Methodology, Software, Validation, Investigation, Formal analysis, Data Curation, Writing-Original Draft, Supervision, Project administration, Writing-Review \& Editing.

Mehmet Özgur Özemre: Conceptualization, Methodology, Software, Validation, Investigation, Formal analysis, Data Curation, Writing-Original Draft, Supervision, Project administration, Writing-Review \& Editing. Canan Uzun: Software, Data Curation.

Büyük Kaan Orhan: Software, Data Curation.

Ayse Gulsahi: Conceptualization, Methodology, Writing-Review \& Editing.

Paul van der Stelt: Methodology, Data Curation, Supervision, Writing-Review \& Editing

Oya Şeker: Review the Literature and Supervision.

Kıvanc Kamburoglu: Conceptualization, Methodology, Writing-Review \& Editing. 


\section{References}

1. Nickenig HJ, et al. Lingual concavities in the mandible: A morphological study using cross-sectional analysis determined by CBCT. J Craniomaxillofac Surg 2015;43(2):254-59.

2. Chan HL, et al. Cross-sectional analysis of the mandibular lingual concavity using cone beam computed tomography. Clin Oral Impt Res 2011;22(2):201-6.

3. Bodart L, et al. Assessing the frequency of deep lingual concavities in 826 posterior mandible sockets. J Craniomaxillofac Surg 2020;48(11):1045-51.

4. Kamburoğlu K, et al. CBCT quantitative evaluation of mandibular lingual concavities in dental implant patients. Surg Radiol Anat 2015;37(11):1209-15

5. Watanabe $\mathrm{H}$, et al. Mandible size and morphology determined with CT on a premise of dental implant operation. Surg Radiol Anat 2010;32(4):343-49.

6. Tyndall DA, et al. Position statement of the American Academy of Oral and Maxillofacial radiology on selection criteria for the use of radiology in dental implantology with emphasis on cone beam computed tomography. Oral Surg Oral Med Oral Pathol Oral Radiol 2012;113(6):817-26.

7. White SC, Pharoah MJ. Oral Radiology: Principles and Interpretation. Mosby/Elsevier 2014:524-41

8. Scarfe WC, Farman AG. What is cone-beam CT and how does it work? Dent Clin N Am 2008; 52(4):707-30.

9. Kamburoğlu K. Use of dentomaxillofacial cone beam computed tomography in dentistry. World J Radiol 2015;7(6):128-30.

10. Pauwels R, et al. Technical aspects of dental cone-beam CT: state of the art. Dentomaxillofac Radiol 2015;44(1):120140224.

11. European Commission; Cone Beam CT for Dental and Maxillofacial Radiology (Evidence- based guidelines). Radiation Protection No172 2012;26-8.

12. Parnia F, et al. Tomographic volume evaluation of submandibular fossa in patients requiring dental implants. Oral Surg Oral Med Oral Pathol Oral Radiol Endod 2010;109(1):e32-6.

13. Shiratori LN, et al. Measurement of buccal bone volume of dental implants by means of cone-beam computed tomography. Clin Oral Impl Res 2012;23(7):797-804.

14. Aytac O, Kurtdas MC. Social origins of health-disease and health sociology. Firat University Journal of Social Sciences 2015;25(1):231-50.

15. Fleiss JL, Levin BA, Paik MC. Statistical Methods for Rates and Proportions (2nd edn). New York: John Wiley, 1981.

16. Han, X. On Statistical Measures for Data Quality Evaluation. J Geogr Inf Syst 2020;12(3):178-187.

17. Haj Yahya B, Chaushu G, Hamzani Y. Computed tomography for the assessment of the potential risk following implant placement in fresh extraction sites in the posterior mandible. J Oral Implantol 2021;47(1):2-8.

18. Angelopoulos $\mathrm{C}$, et al. Comparison between digital panoramic radiography and cone-beam computed tomography for the identification of the MC as part of presurgical dental implant assessment. J Oral Maxillofac Surg 2008;66(10):2130-35.

19. Gahleitner A, Watzek G, Imhof H. Dental CT: imaging technique, anatomy, and pathologic conditions of the jaws. Eur Radiol 2003;13(2):366-76.

20. Herranz-Aparicio J, et al. Retrospective study of the bone morphology in the posterior mandibular region. Evaluation of the prevalence and the degree of lingual concavity and their possible complications. Med Oral Patol Oral Cir Bucal 2016;21(6):e731-36.

21. Priyadarshini SR, et al. Qualitative and morphological evaluation of the mandibular bone using computed tomography. Indian J Dent Res 2020;31(6):899-903. 